\title{
NOTE ON DIOECY IN THE CRUCIFERAE
}

\author{
A. J. BATEMAN \\ Christie Hospital and Holt Radium Institute, Manchester \\ (British Empire Cancer Campaign Fellow)
}

I have just learnt that there is one known exception to the assertion in my paper, "Self-incompatibility systems in angiosperms. III. Cruciferae" (Heredity, 9, 53-63) that there was no dioecy in that family. Dr E. J. Godley, of the Crop Research Division of New Zealand, has kindly drawn my attention to Lepidium sisymbrioides Hook., which he knows from direct observation to be dioecious. This fact was first noted by Kirk (1899) in Studies in the Flora of New Zealand, but it was overlooked by Prantl. Thus we find that the predominantly inbreeding genus Lepidium also has an outbreeding species, though its outbreeding mechanism is alien to the rest of the family.

Two alternative explanations occur to me. Firstly, whilst self-incompatibility was present early in, if not at the origin of the family, $L$. sisymbrioides might represent the secondary evolution of outbreeding from inbreeding ancestors.

Secondly, the sex-determining factor might have arisen directly from the S-gene. Such a process was envisaged by me in 1952 (Heredity, 6, p. 297, case $G$ ). In an isolated population with the Crucifer type of incompatibility and too few alleles for it to function properly (a minimum of two), there would be selective pressure towards such a solution. Capsella grandiflora, if it really has only three alleles, has just missed such a situation by one allele. 